\title{
ANAESTHETIC MANAGEMENT OF TETRALOGY OF FALLOT COMING FOR NON-CARDIAC SURGERY: A CASE REPORT
}

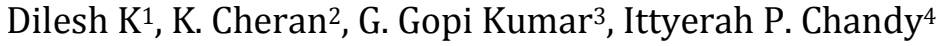

\section{HOW TO CITE THIS ARTICLE:}

Dilesh K, K. Cheran, G. Gopi Kumar, Ittyerah P. Chandy. "Anaesthetic Management of Tetralogy of Fallot Coming for non-Cardiac Surgery: A Case Report". Journal of Evolution of Medical and Dental Sciences 2015; Vol. 4, Issue 23, March 19; Page: 4029-4032, DOI: 10.14260/jemds/2015/579

ABSTRACT: Tetralogy of Fallot is a cyanotic congenital heart disorder and includes ventricular septal defect, right ventricular outflow tract obstruction (pulmonic stenosis), right ventricular hypertrophy and overriding of aorta. Anaesthetic goals in these patients is to maintain or increase the systemic vascular resistance minimize pulmonary vascular resistance and provide mild cardiac depression. Here we present a report of anaesthetic management of a 5 year old boy with tetralogy of fallot coming for cleft lip and cleft palate repair.

KEYWORDS: Tetralogy of Fallot, Cyanotic congenital heart disorder, Ventricular septal defect, Right ventricular outflow tract obstruction, Right ventricular hypertrophy, Overriding of aorta, Anaesthetic management

INTRODUCTION: Congenital heart disease (CHD) is the most common among birth defects accounting for approximately 1 in 125 live births. Lot of them present for surgical correction for cleft lip and palate, tracheoesophageal fistula, anorectal anomalies and renal and skeletal pathologies.[1] The anaesthesiologist faces challenges in handling these patients coming for noncardiac surgery. A diagnosis of congenital heart disease increases the mortality risk for noncardiac surgery. ${ }^{[2]}$ Here we present a case report of a case of tetralogy of fallot (TOF) coming for elective cleft lip and cleft palate repair.

MATERIALS AND METHODS: A 5 year old male child presented with cleft lip and cleft palate for repair in Vinayaka missions medical college and hospital, Karaikal. The child presented to the preanaesthetic clinic for fitness for surgery. History was obtained from his mother. He was born at full term by cesarean section and was diagnosed for tetralogy of fallot. He never underwent any surgical correction. There was history of breathlessness on mild to moderate exertion and history of squatting. There was no history of delay in milestones and he was immunized for age. He was not on any medication.

On Examination the child was $15 \mathrm{kgs}$ of weight and $95 \mathrm{~cm}$ height. He had clubbing, central cyanosis, heart rate of 102 per minute, respiratory rate of 18 per minute and blood pressure of 96/54 $\mathrm{mm}$ of $\mathrm{Hg}$. On examination of cardio vascular system, he had a parasternal heave and a pansystolic murmur and accompanying thrill. Respiratory system, Central nervous system and per abdomen examination was normal. Pulse oximetry showed $82-84 \%$ saturation on room air. On investigation, his $\mathrm{Hb}$ was $16 \mathrm{~g} \%$, TLC - 8000 cells/cumm, urea $-36 \mathrm{mg} \%$, blood group - B +ve, bleeding time $-3 \mathrm{~min}$ 00 seconds and clotting time -4 min 30 seconds, Chest x ray- RV type apex and ECG showed right axis deviation with a regular rate of $100 /$ minute. ECHO showed large Ventricular septal defect with overriding of aorta, severe pulmonary stenosis, right ventricular and right atrial hypertrophy and patent foramen ovale and severe pulmonary hypertension. Parents were not willing for correction of TOF. 
A cardiologist opinion was sought and it was decided to do the surgery under high risk consent. The boy was kept nil per oral for 6 hours duration. Infective endocarditis prophylaxis was given to the boy 1 hour before the procedure and IV crystalloids started at a rate of $50 \mathrm{ml}$ per hour. His room air saturation was $81-83 \%$ only. He was given midazolam $0.5 \mathrm{mg}$ iv and was shifted to the operating room and all monitors including pulse oximeter, non-invasive blood pressure, and electrocardiogram and capnogram were attached. He was preoxygenated, ketamine 45mg, fentanyl 15 mic and inj atracurium 7. $5 \mathrm{mg}$ were given iv and was intubated with 5 size cuffed RAE tube. Bilateral air entry was checked and tube was fixed at $14 \mathrm{~cm}$.

An inftraorbital nerve block was given with $2 \mathrm{ml}$ of $0.5 \%$ bupivacaine. Anaesthesia was maintained with sevoflurane, oxygen and air mixture. Atracurium was used to maintain muscle paralysis. His saturation improved and maintained at $94-96 \%$ throughout the surgery. Blood pressure of $110 / 60$ and heart rate of 100 was maintained throughout the procedure. Surgery lasted 90 minutes and the boy was reversed with neostigmine $0.75 \mathrm{mg}$ and glycopyrrolate $0.2 \mathrm{mg}$ iv. He was extubated on table and was stable. Paracetamol rectal suppository was given and he was shifted to post anaesthetic care unit and was monitored for 6 hrs. His vitals were Spo2 of 82-84\%, BP$90 / 60 \mathrm{~mm} \mathrm{hg}$, Heart rate of $100 / \mathrm{min}$. Post-operative period was uneventful and the boy was discharged two days later. He came for follow up one month later and was doing fine.

RESULTS: A 5 year old child with congenital heart disease (Tetralogy of fallot), coming for cleft lip and cleft palate repair was successfully given uneventful general anaesthesia.

DISCUSSION: Neonates born with congenital heart disease is not uncommon. Children with congenital heart disease coming for extra cardiac surgery may be put into three categories:

- $\quad$ Non-operated patient

- With previous palliative surgery and

- With previous corrective surgery.[4]

Tetralogy of fallot accounts for about $10 \%$ of CHD and about $50 \%$ succumb during first year of life. Children surviving this period present with hypoxia, cyanosis, polycythemia, coagulopathies, congestive heart failure and cyanotic spells.

Extra cardiac surgeries carry a much higher risk and the anaesthesiologist must obtain information about the heart lesion, its altered physiology and implications under anaesthesia.[5] Other than Ventricular septal defect, right ventricular outflow tract obstruction (pulmonic stenosis), right ventricular hypertrophy and overriding of aorta, they can have non-cardiac anomalies including musculoskeletal abnormality, neurological defects and genitourinary defects. Patients with down syndrome may have atlanto-occipital subluxation, requiring airway management precautions. $[4,6]$

Patients with congenital heart disease may be on of aspirin, anticoagulants, diuretics and angiotensin converting enzyme (ACE) inhibitors. All cardiac medications should be given on the morning of surgery, ${ }^{[7]}$ with exemption of ACE inhibitors. ${ }^{[8]}$ Low-dose aspirin may be continued. However, for major surgeries, aspirin is discontinued. ${ }^{[9]}$ Children on warfarin must be given bridging anticoagulation prior to surgery.[1,8]

Fasting time orders should be clearly mentioned with timing. Dehydration should be avoided and an IV line should be placed and fluids started. Sympathetic stimulation due to crying can increase 


\section{CASE REPORT}

oxygen consumption and myocardial work; this may be poorly tolerated. Midazolam can be given for premedication to reduce oxygen consumption.[10]

Infective endocarditis is a serious concern and prophylaxis must be given with antibiotics.

Full blood count and coagulation profile should always be requested. Polycythemia increases blood viscosity which leads to thrombosis and infarcts.[11] Preoperative phlebotomy is performed in symptomatic hyperviscosity and hematocrit (HCT) above 65\%. However, dehydration must be corrected first before deciding about phlebotomy. On the other hand, WBC count and C-reactive protein (CRP) measurement provide potential diagnosis of infection.[9]

Serum electrolytes should be checked in patients receiving diuretics. ECG may show ventricular strain or hypertrophy. ECHO is used for Doppler and colour flow mapping.

The chest X-ray shows the heart position and size, atelectasis, acute respiratory infection, vascular markings and elevated hemidiaphragm.[11]

Intra op - Systemic vascular resistance (SVR) and peripheral vascular resistance (PVR) balance should be considered when using intravenous agents. Patients with poor cardiac function, who require inotropes preoperatively, may not tolerate inhalational induction, and favour the use of ketamine. Ketamine was the most common induction agent.[3] Inotropes should be continued and IV induction agents titrated. The need for invasive monitoring should depend on the type of surgery and cardiac lesion. ${ }^{[5]}$ Air bubbles must be prevented as they can be shunted into arterial system causing emboli.

Increase in SVR, decrease the R - L shunting and improve arterial oxygenation. Nitrous oxide is controversial as it could increase PVR and expand any air bubbles causing emboli. Development of cyanotic spell can happen due to spasm of hypertrophied pulmonary infundibulum. Tachycardia and increased myocardial contractility can cause this and must be given thorough consideration. It responds to volume, increase in SVR with alpha agonists such as Phenylephrine or Ephedrine.[12]

Pain management is a critical factor during intra and postoperative management. Opioid infusion for major operations has been the primary postoperative intervention for pain for these patients. ${ }^{[1,3]}$ The use of regional anesthesia for well-compensated patients was reported with no complications. ${ }^{[2][13]}$

Even with favorable outcome, non-cardiac surgery still carries high-risk after operation. [3] Observing them in high-dependency bed or intensive care unit will warrant assurance of catching arrhythmia, cardiac ischaemia, dehydration, pain, ventilator issues and other complications before they cause detrimental effects.

\section{REFERENCES:}

1. White MC. Approach to managing children with heart disease for noncardiac surgery. Paediatr Anaesth. 2011; 21: 522-9. [PubMed].

2. Baum VC, Barton DM, Gutqesell HP. Influence of congenital heart disease on mortality after noncadiac surgery in hospitalized children. Pediatrics. 2000; 105: 332-5. [PubMed].

3. Walker A, Stokes M, Moriarty A. Anesthesia for major general surgery in neonates with complex cardiac defects. Paediatr Anaesth. 2009; 19: 119-25. [PubMed].

4. Walker SG, Stuth EA. Single-ventricle physiology: Perioperative implications. Semin Pediatr Surg. 2004; 13: 188-202. [PubMed]. 
5. Frankville D. Anesthesia for children and adults with congenital heart disease. In: Lake CL, Booker PD, editors. Pediatric Cardiac Anesthesia. Philadelphia: Lippincott Williams and Wilkins; 2005. pp. 601-32.

6. Hastings LA, Wood JC, Harris B, Von Busse S, Drachenberq A, Dorey F, et al. Cardiac medications are not associated with clinically important preoperative electrolyte disturbances in children presenting for cardiac surgery. Anesth Analg. 2008; 107: 1840-7. [PubMed].

7. Diaz LK, Hall S. Anesthesia for non-cardiac surgery and magnetic resonance imaging. In: Andropoulos DB, Stayer SA, Russell IA, editors. Anesthesia for Congenital Heart Disease. Massachusetts: Blackwell Publishing; 2005. pp. 427-52.

8. Colson P, Ryckwaert F, Coriat P. Renin angiotensin system antagonists and anesthesia. Anesth Analg. 1999; 89: 1143-55. [PubMed].

9. Diaz LK, Andropoulos DB. New developments in pediatric cardiac anesthesia. Anesthesiol Clin North America. 2005; 23: 655-76. [PubMed].

10. Cox RG, Nemish U, Ewen A, Crowe MJ. Evidence-based clinical update: Does premedication with oral midazolam lead to improved behavioural outcomes in children? Can J Anaesth. 2006; 53: 1213-9. [PubMed].

11. De Filippis AP, Law K, Curtin S, Eckman JR. Blood is thicker than water: The management of hyperviscosity in adults with cyanotic heart disease. Cardiol Rev. 2007; 15: 31-4. [PubMed].

12. Laird TH, Stayer SA, Rivenes SM, Lewin MB, McKenzie ED, Fraser CD, et al. Pulmonary-tosystemic blood flow ratio effects of sevoflurane, isoflurane, halothane, and fentanyl/midazolam with $100 \%$ oxygen in children with congenital heart disease. Anesth Analg. 2002; 95: 1200-6. [PubMed].

13. Shenkman Z, Johnson VM, Zurakowski D, Arnon S, Sethna NF. Hemodynamic changes during spinal anesthesia in premature infants with congenital heart disease undergoing inguinal hernia correction. Paediatr Anaesth. 2012; 22: 865-70. [PubMed].

\section{AUTHORS:}

1. Dilesh K.

2. K. Cheran

3. G. Gopi Kumar

4. Ittyerah P. Chandy

\section{PARTICULARS OF CONTRIBUTORS:}

1. Final year Post Graduate, Department of Anaesthesiology, Vinayaka Missions Medical College, Karaikal, Pondicherry.

2. Professor \& HOD, Department of Anaesthesiology, Vinayaka Missions Medical College, Karaikal, Pondicherry.

3. $2^{\text {nd }}$ year Diploma, Department of Anaesthesiology, Vinayaka Missions Medical College, Karaikal, Pondicherry.
4. $2^{\text {nd }}$ year Diploma, Department of Anaesthesiology, Vinayaka Missions Medical College, Karaikal, Pondicherry.

\section{NAME ADDRESS EMAIL ID OF THE CORRESPONDING AUTHOR:}

Dilesh K, Alena House, Post Puthiyara, District Calicut-673004, Kerala.

E-mail: dr.dilesh@gmail.com

Date of Submission: 25/02/2015. Date of Peer Review: 26/02/2015. Date of Acceptance: 07/03/2015. Date of Publishing: 18/03/2015. 